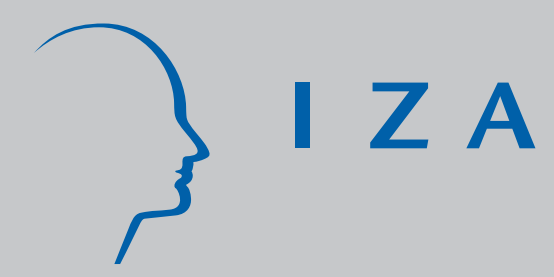

IZA DP No. 3984

Is There Scope for Gains from Revenue-Neutral Labor Tax Reforms with Flexible Outsourcing?

Erkki Koskela

Panu Poutvaara

J anuary 2009 


\title{
Is There Scope for Gains from Revenue-Neutral Labor Tax Reforms with Flexible Outsourcing?
}

\author{
Erkki Koskela \\ University of Helsinki \\ and IZA \\ Panu Poutvaara \\ University of Helsinki \\ and IZA
}

Discussion Paper No. 3984
January 2009

IZA

P.O. Box 7240

53072 Bonn

Germany

Phone: +49-228-3894-0

Fax: +49-228-3894-180

E-mail: iza@iza.org

Any opinions expressed here are those of the author(s) and not those of IZA. Research published in this series may include views on policy, but the institute itself takes no institutional policy positions.

The Institute for the Study of Labor (IZA) in Bonn is a local and virtual international research center and a place of communication between science, politics and business. IZA is an independent nonprofit organization supported by Deutsche Post Foundation. The center is associated with the University of Bonn and offers a stimulating research environment through its international network, workshops and conferences, data service, project support, research visits and doctoral program. IZA engages in (i) original and internationally competitive research in all fields of labor economics, (ii) development of policy concepts, and (iii) dissemination of research results and concepts to the interested public.

IZA Discussion Papers often represent preliminary work and are circulated to encourage discussion. Citation of such a paper should account for its provisional character. A revised version may be available directly from the author. 
IZA Discussion Paper No. 3984

January 2009

\section{ABSTRACT}

\section{Is There Scope for Gains from Revenue-Neutral Labor Tax Reforms with Flexible Outsourcing?}

We study the effects of revenue-neutral labor tax reforms in an imperfectly competitive domestic labor market under Nash wage bargaining and flexible outsourcing. A revenueneutral increase in the wage tax progression will decrease the negotiated wage rate, increase domestic labor demand and decrease international outsourcing. In the presence of wage tax exemption, a lower payroll tax and a higher wage tax will increase domestic labor demand and decrease international outsourcing. The effect on the negotiated wage rate is positive with sufficiently strong labor market imperfections, and ambiguous with sufficiently weak labor market imperfections.

JEL Classification: H11, H22, J41, J51

Keywords: flexible outsourcing, wage bargaining, employment, tax-revenue neutral labor tax reforms

Corresponding author:

Erkki Koskela

Department of Economics

University of Helsinki

P.O. Box 17 (Arkadiankatu 7)

00014 University of Helsinki

Finland

E-mail: erkki.koskela@helsinki.fi 


\section{Introduction}

During the latest decades, outsourcing has become an increasingly important aspect of production. Outsourcing means that part of the production activity is located to another country. Large wage differences across countries are most likely important explanations for this behavior, as the production costs may be substantially reduced if part of the production is located to a country with lower wages. ${ }^{1}$ When outsourcing and domestic labor are substitutes, the domestic labor demand is decreasing and the wage elasticity of domestic labor demand is increasing in the share of outsourcing, which limits the mark-up labor unions can set above the opportunity cost of labor. Outsourcing can take two alternative forms. Firms may write long-term contracts that fix the amount of outsourcing before the labor union sets the wage, i.e. strategic outsourcing, or alternatively firms may be flexible enough later on to decide upon the amount of outsourcing activity simultaneously with the domestic labor demand after the domestic wage is set by the trade union.

In this paper we analyze the government revenue-neutral labor tax reforms, associated with wage tax progression and combination between wage and proportional payroll tax on wage setting, employment and outsourcing in the case of flexible outsourcing under Nash wage bargaining concerning domestic wage determination. ${ }^{2}$ Wage taxation in OECD countries is progressive though the degree of progressivity varies across countries, while payroll taxes are approximately proportional. There is no earlier research on the role of revenue-neutral labor tax reforms in the presence of outsourcing. Throughout the analysis, we assume that the economy is on the upward-

\footnotetext{
1 For a wide range of industries, wage differences across countries constitute central explanations for outsourcing of production; see e.g. Sinn (2007). Of course, the wage differences alone exaggerate the incentives for outsourcing, because these might also reflect productivity differentials. Acemoglu and Zilibotti (2001) present empirical evidence of a mismatch between the new technologies developed in the rich economies and the skills of workers in less developed countries and they argue that this burdens productivity in the less developed countries.

2 Because outsourcing can take two alternative forms, firms may write long-term contracts that fix the amount of outsourcing before the labor union sets the wage. This case has been analyzed by Skaksen and Sörensen (2001). They argue that if there is a high degree of substitutability (complementarity) between the activities in the home country and in the host country, then ít is likely that foreign direct investments reduce (increase) negotiated wages so that domestic worker lose (benefit).
} 
sloping part of the Laffer curve, and wages are determined in Nash bargaining. Also Skaksen (2004) has analyzed the implications of flexible outsourcing for wage setting and employment under imperfectly competitive labor markets, but in the absence of taxation. $^{3}$

With sufficiently strong (weak) labor market imperfections a lower outsourcing cost and higher payroll tax have a wage-moderating (wage-increasing) effect. Polar cases are a monopoly labor union, with which a lower outsourcing cost moderates wages, and the absence of labor market imperfections, in which case there is no relationship between outsourcing cost and wage formation and between payroll tax and wage formation. In the presence of flexible outsourcing the wage tax has a positive effect and the tax exemption a negative effect on the negotiated wage. In the absence of outsourcing the payroll tax will have no effect on wage formation.

Increasing the degree of tax progression has a wage-moderating effect and a positive effect on domestic employment and a negative effect on outsourcing. These qualitative results are qualitatively similar, but quantitatively different both in the case of monopoly labor union and in the absence of outsourcing. Finally, government revenue-neutral fall in the payroll tax and rise in the wage tax increases the negotiated wage rate with sufficiently strong labor market imperfections, and have an ambiguous effect with sufficiently weak labor market imperfections. A lower payroll tax and higher wage tax will increase domestic labor demand and decrease international outsourcing. Also in the absence of outsourcing a lower payroll tax and a higher wage tax will increase domestic labor demand in the presence of wage tax exemption. But if both taxes are proportional, then in the absence of outsourcing the employment outsourcing effects of a change in wage and payroll tax to keep government revenue constant are zero.

3 Danthine and Hunt (1994) have studied the effects of international outsourcing and foreign direct investment (FDI) on wage formation in the home country by showing that higher product market integration implies intensified product market competition, which moderates wage increases in unionised labor markets. Zhao (1998) has studied the impact of FDI on wages and employment, when labor-management bargaining is industry-wide by arguing that FDI reduces the negotiated wage if the union focuses on wages. They have analyzed the effects of outsourcing in the absence of taxation. It is an important new research topic to analyze the effects of taxation also under FDI with domestic and outsourcing labor as other production factors. Hakkala et al. (2009) explore the effects of cross-border acquisitions on wage elasticities empirically. 
This paper proceeds as follows. Section II presents the basic structure of theoretical framework regarding some policy issues associated with various labor taxes, wage formation, outsourcing and domestic labor demand. Domestic labor demand and outsourcing are studied in section III, whereas wage determination through Nash bargaining in the presence of linearly progressive wage tax and proportional payroll tax is studied in section IV. The effects of tax-revenue neutral changes in terms of wage tax progression and in terms of composition of wage tax and payroll tax on domestic wage setting, employment and outsourcing are analyzed in section V. Finally, conclusions are presented in section VI.

\section{Basic Framework}

In this paper the focus is to study the effects of two tax-revenue neutral labor tax on wage negotiation, domestic labor demand and outsourcing in the presence of flexible outsourcing, when domestic labor demand and outsourcing are decided simultaneously after the wage negotiation by the labor union and the firms. The time sequence is described in Figure 1.

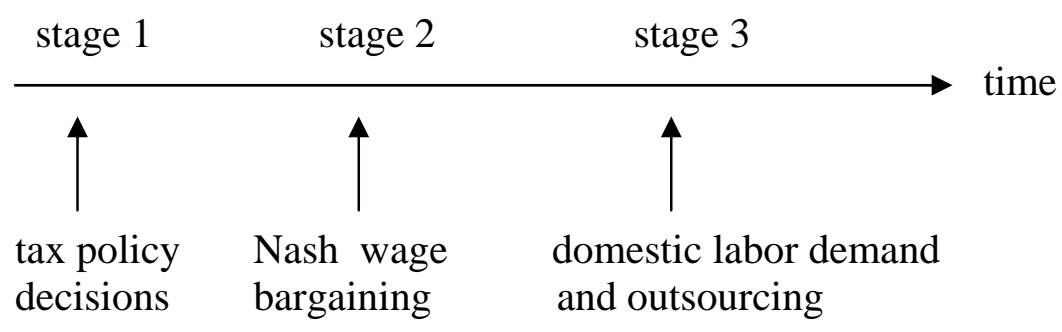

Figure 1: Time sequence of decisions

At stage 1 the government behaves as a Stackelberg leader and fixes labor tax parameters in terms of revenue-neutrality for government. To raise revenues the government can employ a wage tax $t$, which is levied on the wage $w$, minus a tax exemption $a$. The tax base per worker for the wage tax $t$ is $(w-a)$. In the presence of a positive tax exemption $a$, the marginal tax rate $t$ exceeds the average tax rate 
$t(1-a / w)$ so that the tax system is linearly progressive. ${ }^{4}$ The net-of-tax wage, the worker receives, is given by $w^{n}=w(1-t)+t a$. The proportional payroll tax levied on firms is $s$. The wage tax is progressive in OECD countries, while the payroll tax is approximately proportional (source: OECD (2004)) so that we therefore abstract from an additional tax exemption for the payroll tax. At stage 2 the labor union and the firm negotiate on wages using the Nash bargaining approach. They take tax parameters as given and anticipate the consequences that wage setting will have for the domestic labor demand and outsourcing. At stage 3 the domestic labor demand and outsourcing are decided simultaneously by the firm. The decisions at each stage are analyzed by using backward induction.

To derive an explicit solution a decreasing returns to scale production function is presented as

$$
R(L, M)=\frac{\delta}{\delta-1}(L+\gamma M)^{\frac{\delta-1}{\delta}}, \quad \delta>1,
$$

where $L$ is the amount of labor employed in-house and $M$ denotes the firm's labor input acquired from external suppliers through outsourcing. The parameter $\delta>1$ means that the production function is an increasing and concave function of inputs. ${ }^{5}$ The specification (1) of the production function implies that domestic labor and outsourced

For a seminal paper about tax progression, see Musgrave and Thin (1948), and for another elaboration, see e.g. Lambert (2001, chapters 7-8).

5 Specifying the inverse product demand function according to a monopolistic product market competition (see the seminar paper by Dixit and Stiglitz (1977)) as $p=\frac{\delta}{\delta-1} D^{-\frac{1}{\delta}}, \delta>1$ gives the inverse elasticity of demand $-p_{D} D / p=1 / \delta$ which means $-D_{p} p / D=\delta>1$. This paper does not focus on the simultaneous presence of imperfections in labor and product markets so that in this model the wage-moderating effect of outsourcing is independent of potential market structure change in the product market. Lommerud et al. (2006) have demonstrated how international mergers might curb the market power of unions giving socially excessive incentive for international mergers, unless products are close substitutes. A somewhat related wagemoderating effect of foreign investments is developed in Eckel and Egger (2006). They focus on duopoly competition within a framework where the firms can produce either in one or both of two identical countries. Within such a framework foreign market penetration induces a wagemoderating effect in a unionized economy, because it improves the firm's outside option relevant for the wage negotiations. In these papers they abstract from taxation issues. 
input are substitutes with a productivity differential. The parameter $\gamma>0$ captures the productivity of outsourcing relative to the domestic labor input. ${ }^{6}$

The analysis starts with an investigation of domestic labor demand and outsourcing and in the subsequent sections wage bargaining and tax policies are characterized by applying backward induction.

\section{Domestic Labor Demand and Outsourcing}

At the last stage the firm decides simultaneously on domestic in-house employment $L$ and outsourcing $M$ to maximize the profit function

$$
\underbrace{\operatorname{Max}}_{L, M} \pi=\frac{\delta}{\delta-1}(L+\gamma M)^{\frac{\delta-1}{\delta}}-w(1+s) L-g(M) .
$$

When deciding on its labor demand and outsourcing, each firm takes as given the gross wage for labor, $\tilde{w}=w(1+s)$, where $s$ is the proportional payroll tax levied on the firm. In order to obtain $M$ units of outsourced unskilled labor input, we assume that firms have to spend $g(M)=0,5 c M^{2}$ with $g^{\prime}(M)=c M>0$ and $g^{\prime \prime}(M)=c>0$. An increasing marginal cost of outsourcing is assumed to capture the idea that some activities are easier to outsource than others.

The first-order conditions are

$$
\begin{aligned}
& \pi_{L}=(L+\gamma M)^{-\frac{1}{\delta}}-w(1+s)=0, \\
& \pi_{M}=(L+\gamma M)^{-\frac{1}{\delta}} \gamma-c M=0
\end{aligned}
$$

and equations (3a) and (3b) give the following explicit domestic labor demand and

Ethier (2005) has introduced a somewhat related production function to analyze the decision between outsourcing and in-house production focusing on the effects of globalization on the skill premium. 
outsourcing $^{7}$

$$
\begin{gathered}
L=(w(1+s))^{-\delta}-\gamma M=(w(1+s))^{-\delta}-\gamma\left(\frac{\gamma w(1+s)}{c}\right), \\
M=\frac{\gamma w(1+s)}{c} .
\end{gathered}
$$

Domestic labor demand is a negative function of the domestic gross wage rate and the productivity of outsourcing, and a positive function of the cost of outsourcing, while outsourcing is a positive function of the domestic gross wage rate and productivity of outsourcing and a negative function of the cost of outsourcing. This means that higher outsourcing will decrease domestic labor demand. ${ }^{8}$ Higher payroll tax will decrease domestic labour demand and increase outsourcing, ceteris paribus.

The outsourcing elasticities in terms of outsourcing cost, productivity of outsourcing, domestic wage and payroll tax are: $-\frac{M_{c} c}{M}=1, \frac{M_{\gamma} \gamma}{M}=1, \frac{M_{w} w}{M}=1$ and $\frac{M_{s}(1+s)}{M}=1$

The wage elasticity and the payroll tax elasticity of labor demand under flexible outsourcing can be expressed as

$$
\eta^{f}(w, s, c, \gamma) \equiv-\frac{L_{w} w}{L}=\frac{\delta(w(1+s))^{-\delta}+\gamma^{2} \frac{w(1+s)}{c}}{L}=\delta\left(1+\gamma \frac{M^{*}}{L^{*}}\right)+\frac{\gamma M^{*}}{L^{*}}=-\frac{L_{s}(1+s)}{L} .
$$

and these depend on parameters $\gamma, w, s$ and $c .{ }^{9}$ In the case of production function (1) in the absence of outsourcing the wage elasticity and the payroll tax elasticity of labor demand are constant, i.e. $\left.\eta\right|_{M=0} \equiv-\frac{L_{w} w}{L}=\delta=-\frac{L_{s}(1+s)}{L}$.

$7 \quad$ The associated second-order conditions are $\pi_{L L}=-\frac{1}{\delta}(L+\gamma M)^{-\frac{(1+\delta)}{\delta}}<0$, $\pi_{M M}=\gamma^{2} \pi_{L L}-c<0$ and $\pi_{L L} \pi_{M M}-\left(\pi_{L M}\right)^{2}=-c \pi_{L L}>0$.

$8 \quad$ See e.g. Görg and Hanley (2005) and Hijzen et al. (2005) for evidence based on various data sets. 9 The production function (1) has been analyzed by Koskela and Stenbacka (2008) by studying the impact of strategic outsourcing on equilibrium unemployment in the absence of labor taxation. 
The relationship between the wage rate and the wage elasticity of domestic labor demand is positive

$$
\eta_{w}^{f}=(1+\delta) \gamma\left[\frac{L M_{w}-M L_{w}}{L^{2}}\right]=\left(1+\eta^{f}\right)(1+\delta) \gamma \frac{M^{*}}{w L^{*}}>0
$$

and the relationship between the outsourcing cost and the wage elasticity of domestic labor demand is negative

$$
\eta_{c}^{f}=(1+\delta) \gamma\left[\frac{L M_{c}-M L_{c}}{L^{2}}\right]=-(1+\delta) \gamma \frac{M^{*}}{c L^{*}}\left(1+\gamma \frac{M^{*}}{L^{*}}\right)<0
$$

Higher outsourcing due to lower outsourcing cost will increase the wage elasticity (and payroll tax elasticity) of domestic labor demand, which lies in conformity with empirical evidence from various data sets. Senses (2006) has provided empirical evidence according to which a production mode with more outsourcing seems to increase the wage elasticity of labour demand. Also Slaughter (2001) and Hasan et al. (2007) have shown that international trade has increased the wage elasticity of labour demand. ${ }^{10}$

The relationship between the payroll tax and the wage elasticity of domestic labor demand is also positive, i.e.

$$
\eta_{s}^{f}=(1+\delta) \gamma\left[\frac{L M_{s}-M L_{s}}{L^{2}}\right]=\left(1+\eta^{f}\right)(1+\delta) \gamma \frac{M^{*}}{(1+s) L^{*}}>0
$$

10 Lommerud et al. (2009) have presented a theoretical model with monopolistic competition to determine how unionization affects the fraction of outsourced inputs. In their model they argue that in equilibrium stronger labor market imperfections decrease the fraction of outsourced inputs because higher outsourcing reduces the wage elasticity for the components produced in-house, thereby leading to higher domestic wage. This does not lie in conformity with empirical evidence which has been mentioned. Lommerud et al. (2009) have abstracted from taxation issues which has our focus in this paper. 
One can also show that higher productivity of outsourcing will increase the wage elasticity, i.e. $\eta_{\gamma}^{f}>0$.

\section{Wage Determination via Nash Bargaining under Linearly Progressive Wage Tax and Proportional Payroll Tax}

We now proceed to investigate wage determination by applying the Nash bargaining solution following the right-to-manage (RTM) approach (see e.g. Cahuc and Zylberberg (2004), Ch 7) so that wage negotiation takes place in anticipation of optimal domestic labor and outsourcing decisions. The labor union's objective function in the presence of linearly progressive wage taxation is assumed to be $\hat{U}=(w(1-t)+t a) L^{*}+b\left(N-L^{*}\right)$, where the tax base for the wage tax $t$ equa1s $(w-a) L^{*}$, where there is a positive tax exemption $a . b$ is the (exogenous) outside option available to union members and $N$ is the number of union members $\left(N \geq L^{*}\right)$ and the threat point is $U^{o}=N b$ so that the relevant objective function of the labor union is $U=\hat{U}-N b=L^{*}(w(1-t)+t a-b)$.

Following the Nash bargaining approach the firm and the labor union negotiate with respect to wage rate so as to solve the following optimization problem

$$
\begin{gathered}
\underbrace{\operatorname{Max}}_{w} \Omega=\left[L^{*}(w(1-t)+t a-b)\right]^{\beta}\left[R\left(L^{*}, M^{*}\right)-w(1+s) L^{*}-\frac{1}{2} c M^{* 2}\right]^{1-\beta} \\
\text { s.t. } \quad L=(w(1+s))^{-\delta}-\gamma\left(\frac{\gamma w(1+s)}{c}\right),
\end{gathered}
$$

where $\frac{\not w(1+s)}{c}=M^{*}$ is the optimal flexible outsourcing and the relative bargaining power of the labor union is $\beta$ and that of the firm is $1-\beta$. The first-order condition for the negotiated wage rate can be written as 


$$
\Omega_{w}=0 \Leftrightarrow \beta \frac{U_{w}}{U}+(1-\beta) \frac{\pi_{w}^{*}}{\pi^{*}}=0,
$$

where

$$
\frac{U_{w}}{U}=\frac{1}{w}\left[\frac{w\left(1-\eta^{f}(w, s, c, \gamma)\right)(1-t)+\eta^{f}(w, s, c, \gamma)(b-t a)}{w(1-t)-(b-t a)}\right]>0,
$$

and

$$
\frac{\pi_{w}^{*}}{\pi^{*}}=-\frac{1}{w} \frac{w(1+s) L}{\pi}=-\frac{1}{w} \frac{R_{L} L}{\left[R-R_{L} L-\frac{1}{2} R_{M} M\right]}=-\frac{1}{w} \frac{2(\delta-1)}{\left[2-\delta+\eta^{f}\right]} .
$$

where $2-\delta+\eta^{f}=2+(1+\delta) \frac{M^{*}}{L^{*}}$ (see Appendix A concerning (9b)).

Substituting the equations (9a) and (9b) into the first-order condition (8) gives after calculations the following Nash bargaining solution for the negotiated wage (see Appendix A)

$$
w^{N}=\frac{\beta \eta^{f}\left(2-\delta+\eta^{f}\right)+(1-\beta) 2(\delta-1)}{\beta\left(\eta^{f}-1\right)\left(2-\delta+\eta^{f}\right)+(1-\beta) 2(\delta-1)} \hat{b}=A^{f} \hat{b},
$$

where the outside option in the presence of tax parameters is $\hat{b}=\frac{b-t a}{1-t}$ and using the notation $Z=2+(1+\delta) \gamma \frac{M^{*}}{L^{*}}$ and $\eta^{f}-\delta=(1+\delta) \gamma \frac{M^{*}}{L^{*}}$ the mark-up $A^{f}$ can be written

$$
A^{f}=\frac{\beta \eta^{f}\left(2+(1+\delta) \gamma \frac{M^{*}}{L^{*}}\right)+(1-\beta) 2(\delta-1)}{\beta\left(\eta^{f}-1\right)\left(2+(1+\delta) \gamma \frac{M^{*}}{L^{*}}\right)+(1-\beta) 2(\delta-1)}=\frac{\beta \eta^{f} Z+(1-\beta) 2(\delta-1)}{\beta\left(\eta^{f}-1\right) Z+(1-\beta) 2(\delta-1)}>1 \quad \text { as }
$$

$1 \geq \beta>0$. The mark-up is not dependent on wage tax parameters, but it is affected by the payroll tax in the presence of outsourcing because payroll tax will affect the wage elasticity of domestic labor demand (see equation (6c)). In the absence of outsourcing 
the Nash wage bargaining solution is $\left.w^{N}\right|_{M=0}=\frac{(\delta-1+\beta)}{(\delta-1)} \hat{b}=A \hat{b}$, which only depends on wage tax parameters, bargaining power to the labor union and decreasing returns to scale of production function, but in the case of production function (1) payroll tax will have no effect on the mark-up.

It is important to mention that equation (10) is not an explicit form for the wage rate under outsourcing because the mark-up both in terms of the numerator and the denominator also depends in a non-linear way on the wage ratio via the ratio between outsourcing and domestic labor demand (see equation (4a)). According to (10) the negotiated wage rate depends positively both on the outside option including tax parameters, $\hat{b}$, and the relative bargaining power of the labor union, $\beta$, and negatively on the wage elasticity of domestic labor demand, $\eta^{f}$.

In the case of the monopoly labor union with outsourcing we have also the following implicit form from (10)

$$
\left.w^{N}\right|_{\beta=1}=\frac{\eta^{f}\left(2-\delta+\eta^{f}\right)}{\left(\eta^{f}-1\right)\left(2-\delta+\eta^{f}\right)} \hat{b}=\frac{\eta^{f}}{\left(\eta^{f}-1\right)} \hat{b}
$$

In the absence of outsourcing the Nash wage bargaining solution (10) for the wage rate is explicit, i.e. $\left.w^{N}\right|_{M=0}=\frac{\beta+\delta-1}{(\delta-1)} \hat{b}$ as well as in the case of monopoly labor union, i.e. $\left.w^{N}\right|_{\beta=1, M=0}=\frac{\delta}{(\delta-1)} \hat{b}$ and if $\beta=0$, then $\left.w^{N}\right|_{\beta=0, M>0}=\left.w^{N}\right|_{\beta=0, M=0}=\hat{b}$. In these cases the payroll tax will have no effect on the mark-up and therefore no effect on wage formation by using the production function (1), i.e. $\left.\frac{\partial w^{N}}{\partial s}\right|_{M=0}=0$.

By differentiating the negotiated wage (10) with respect to the outsourcing cost $c$ gives (see Appendix B)

$$
\frac{\partial w^{N}}{\partial c}=\frac{\frac{A_{c}^{f} w}{A^{f}}}{1-\frac{A_{w}^{f} w}{A^{f}}}\left\{\begin{array}{l}
> \\
= \\
<
\end{array}\right\} 0 \text { if } \beta\left\{\begin{array}{l}
> \\
= \\
<
\end{array}\right\} F,
$$


where $1-\frac{A_{w}^{f} w}{A^{f}}>0$, and $F \equiv \frac{2(\delta-1)}{\left(2+(1+\delta) \gamma \frac{M^{*}}{L^{*}}\right)^{2}+2(\delta-1)}$. The relationship

characterizes how the lower outsourcing cost can decrease wage setting if the relative bargaining power of labor union is higher than the low threshold $F$, where $2+(1+\delta) \gamma \frac{M^{*}}{L^{*}}=2+\eta^{f}-\delta$. This threshold, which is strictly between zero and one, is inversely related to the wage elasticity $\eta^{f}$. Lower outsourcing cost increases the wage elasticity of domestic labor demand by decreasing the mark-up. This is the dominant effect as long as the labor union has a sufficiently strong bargaining power. However, as (8) makes clear, the wage is predominantly determined by the negative effects on profits when the labor union has a sufficiently low bargaining power. Under such circumstances increased outsourcing due to lower outsourcing cost moderates the profit-reducing effect of a higher wage. In this case more outsourcing induces an increase in the wage when the bargaining power lies with the firm to a sufficient degree.

Under the monopoly labor union the mark-up is $\left.A^{f}\right|_{\beta=1}=\frac{\eta^{f}}{\eta^{f}-1}$ so that in this case the lower outsourcing cost will decrease the mark-up, i.e. $\left.A_{c}^{f}\right|_{\beta=1}=\frac{-\eta_{c}^{f}}{\left(\eta^{f}-1\right)^{2}}>0$. In the absence of labor market imperfections, this effect is zero.

By differentiating the negotiated wage (10) with respect to the payroll tax $\mathrm{S}$ gives (see Appendix B)

$$
\frac{\partial w^{N}}{\partial s}=\frac{\frac{A_{s}^{f} w}{A^{f}}}{1-\frac{A_{w}^{f} w}{A^{f}}}\left\{\begin{array}{l}
< \\
=
\end{array}\right\} 0 \text { if } \beta\left\{\begin{array}{l}
> \\
= \\
<
\end{array}\right\} F
$$

where $1-\frac{A_{w}^{f} w}{A^{f}}>0$ and $\beta\left\{\begin{array}{l}> \\ = \\ <\end{array}\right\} F \equiv \frac{2(\delta-1)}{\left(2+(1+\delta) \gamma \frac{M^{*}}{L^{*}}\right)^{2}+2(\delta-1)}$. The relationship 
(13) characterizes how the higher payroll tax can decrease wage if the relative bargaining power of labor union is higher than the low threshold $F$. This threshold, as we mentioned earlier, is inversely related to the wage elasticity. Higher payroll tax increases the wage elasticity of domestic labor demand by decreasing the mark-up. This is the dominant effect as long as the labor union has a sufficiently strong bargaining power. Also wage is affected by the negative effect on profit according to (9b) and when the labor union has a sufficiently low bargaining power, higher outsourcing due to higher payroll tax moderates the profit reducing effect of a higher wage.

Under the monopoly labor union, where $\left.A^{f}\right|_{\beta=1}=\frac{\eta^{f}}{\eta^{f}-1}$, so that in this case the higher payroll tax will decrease the mark-up, i.e. $\left.A_{s}^{f}\right|_{\beta=1}=\frac{-\eta_{s}^{f}}{\left(\eta^{f}-1\right)^{2}}<0$, but there will be no effect in the absence of outsourcing in the case of production function (1), because $\left.\eta_{s}^{f}\right|_{M=0}=0$. In the absence of labor market imperfections, this effect is also zero.

In terms of the wage tax and the tax exemption differentiating (10) gives

$$
\begin{aligned}
& \frac{\partial w^{N}}{\partial t}=\frac{A^{f}}{\left(1-\frac{A_{w}^{f} w}{A^{f}}\right)} \frac{b-a}{(1-t)^{2}}>0 \text { as } b-a>0, \\
& \frac{\partial w^{N}}{\partial a}=-\frac{A^{f}}{\left(1-\frac{A_{w}^{f} w}{A^{f}}\right)} \frac{t}{(1-t)}<0 .
\end{aligned}
$$

In the case of monopoly trade union, $\beta=1$, these findings (14a) and (14b) are qualitatively similar, because these tax parameters only affect via the outside option $\hat{b}=\frac{b-t a}{1-t}$, and not via the mark-up of wage formation. It is also easy to show that in the absence of outsourcing we have qualitatively similar results, i.e. 
$\left.\frac{\partial w^{N}}{\partial t}\right|_{M=0}=\left(\frac{\beta+\delta-1}{\delta-1}\right) \frac{b-a}{(1-t)^{2}}>0$ as $b-a>0$ and $\left.\frac{\partial w^{N}}{\partial a}\right|_{M=0}=-\left(\frac{\beta+\delta-1}{\delta-1}\right) \frac{t}{(1-t)}<0$.

These results can be summarized in

Proposition 1: In the presence of flexible outsourcing

(a) with sufficiently strong (weak) labor market imperfections under Nash wage bargaining a lower outsourcing cost and higher payroll tax have a wage-moderating (wage-increasing) effect, and

(b) with a monopoly labor union, a lower outsourcing cost moderates wages and in the absence of labor market imperfections there is no relationship between outsourcing cost and wage formation and between payroll tax and wage formation, and

(c) in the absence of outsourcing payroll tax will have no effect on wage formation, whereas

(d) both in the presence and in the absence of flexible outsourcing the wage tax has a positive effect and the tax exemption a negative effect on negotiated wage.

According to these findings both lower outsourcing cost and higher payroll tax will have a wage moderating effect under Nash wage bargaining as long as the labor union has a sufficiently strong bargaining power. Of course, this fully works in the case of monopoly labor union.

\section{The Impacts of Revenue-Neutral Labor Tax Reforms on Wage Formation, Employment and Outsourcing}

We now turn to analyze the impacts of tax-revenue neutral changes in wage tax progression and of the composition of wage tax and payroll tax on the negotiated wage, domestic employment and outsourcing. 


\section{V.1. Revenue-neutral increase in wage tax progression}

Here the analysis concentrates on the effects of wage tax progression under government revenue-neutrality for wage formation, employment and outsourcing. ${ }^{11}$ The average tax rate progression ( $A R P$ ) is given by the difference between the marginal tax rate $t$ and the average tax rate $t^{a}=t\left(1-\frac{a}{w}\right)$. The tax system is progressive if $A R P \equiv t-t^{a}=\frac{t a}{w}$ is positive and tax progression is increased if $t-t^{a}$ increases.

Government can raise the degree of tax progression when it increases $t$ and adjusts $a$ upwards. The effect of wage tax progression - which keeps the government tax-revenue $G=\left[t\left(w^{N}-a\right)+s w^{N}\right] L$ constant - can be written in terms of wage tax $t$, tax exemption $a$ and by allowing change in wage formation $w^{N}$ in the following way: $d G=0=\left(w^{N}-a\right) L d t-t L d a+\left((t+s) L+\left(t\left(w^{N}-a\right)+s w^{N}\right) L_{w}\right) d w^{N}$. This can be written in the absence of change in the payroll tax $s$ by using equation (5), i.e. $-\frac{L_{w} w}{L}=\eta^{f}$, as

$$
\left.d a\right|_{d G=0, d s=0}=\frac{\left(w^{N}-a\right)}{t} d t+\left[\left(1+\frac{s}{t}\right)\left(1-\eta^{f}\right)+\frac{a}{w^{N}} \eta^{f}\right] d w^{N} .
$$

The total effect of changes in tax parameters $t$ and $a$ on the negotiated domestic wage rate is $d w^{N}=\frac{\partial w^{N}}{\partial t} d t+\frac{\partial w^{N}}{\partial a} d a$ and substituting the RHS of (15) for $d a$ gives

$$
\left.\frac{d w^{N}}{d t}\right|_{d G=0, d s=0}=\frac{\frac{\partial w^{N}}{\partial t}+\left(\frac{\left.w^{N}-a\right)}{t}\right) \frac{\partial w^{N}}{\partial a}}{D}<0,
$$

11 In the case of flexible outsourcing and Nash wage bargaining Koskela (2008) has not analyzed the role of composition of wage tax and payroll tax, but analyzed the issue by concentrating on the effects of tax progression in the case of tax reform that increases tax progression, while keeping the average tax burden per worker constant and therefore by abstracting from the fully- balanced public sector tax-revenue. Therefore, the focus here is new in the presence of flexible outsourcing. 
where $\underbrace{\frac{\partial w^{N}}{\partial t}}_{+}+\left(\frac{\left.w^{N}-a\right)}{t}\right) \underbrace{\frac{\partial w^{N}}{\partial a}}_{-}<0$ and $D=1-\frac{\partial w^{N}}{\partial a}\left[\left(1+\frac{s}{t}\right)\left(1-\eta^{f}\right)+\frac{a}{w^{N}} \eta^{f}\right]>0$ in the assumption of the presence of the positive Laffer curve ${ }^{12}$ (see Appendix C). Higher wage tax will have a positive effect on wage, and higher tax exemption a negative effect and the latter effect in the nominator of (16) dominates. Concerning the sign of denominator tax exemption affects the tax revenue $G$ both directly and also indirectly via behavioral responses. If the direct effect dominates under the positive Laffer curve, then the relationship between tax revenue and tax exemption is positive. This implies that tax revenue is negatively related to tax exemption $a$ so that and the relationship between tax revenue and tax exemption is negative which means that $D>0$ (see equation (C2) in Appendix C). Hence in the case of the positive Laffer curve the revenue neutral increase in wage tax progression will moderate the negotiated wage under Nash wage bargaining. ${ }^{13}$ In the absence of outsourcing the qualitative finding is similar, i.e. $\left.\frac{d w^{N}}{d t}\right|_{d G=0, d s=0, d M=0}<0 \cdot^{14}$

The total employment and outsourcing effects of changes in wage tax parameters $t$ and $a$ and in the negotiated wage on employment and outsourcing are $d L=L_{w} d w^{N}$ and $d M=M_{w} d w^{N}$, which give using (4a), (4b) and (16) as follows

12 Trabandt and Uhlig (2006) have examined the shape of the Laffer curve to the US as well as to the EU-15 economy over the period 1975-2000. According to their model the US and the EU-15 area are located on the left side of their Laffer curve, i.e. in the case of positive Laffer curve. Using the US data Fullerton (1982) also earlier argued that the notion of an inverse relationship between major U.S. tax rates and government revenues does not work.

13 Koskela (2008) has provided a qualitative similar result but by keeping the average tax burden per worker constant and by abstracting from the fully-balanced public sector tax-revenue. Koskela and Schöb (2008) have analyzed also the impact of labor tax reform changes in the wage tax rate, the tax exemption by increasing the degree of tax progression to keep the relative tax burden per worker constant in the case of monopoly labor union both in the case of strategic and flexible outsourcing and they received the same qualitative result.

14 See e.g. Koskela and Vilmunen (1996), where this has been analyzed both in the absence of outsourcing and without the payroll tax levied on the firms. Equation (C1) from Appendix C can be written in the absence of outsourcing as follows $\frac{\partial w^{N}}{\partial t}+\left(\frac{\left.w^{N}-a\right)}{t}\right) \frac{\partial w^{N}}{\partial a}=\frac{(\beta+\delta-1)}{(\delta-1)(1-t)}\left[\hat{b}-w^{N}\right]_{M=0}<0$. 


$$
\begin{gathered}
\left.\frac{d L}{d t}\right|_{d G=0, d s=0}=\left.\underbrace{L_{w}}_{-} \frac{d w^{N}}{d t}\right|_{d G=0, d s=0}>0, \\
\left.\frac{d M}{d t}\right|_{d G=0, d s=0}=\left.\underbrace{M_{w}}_{+} \frac{d w^{N}}{d t}\right|_{d G=0, d s=0}<0,
\end{gathered}
$$

so that under the positive Laffer curve assumption a revenue-neutral increase in wage tax progression will increase domestic employment and decrease international outsourcing.

We can now summarize our findings of revenue-neutral change in wage tax progression in terms of wage formation, domestic employment and international outsourcing as follows.

Proposition 2: In the presence of flexible outsourcing and imperfectly competitive domestic labor markets

(a) a higher wage tax and higher tax exemption under government revenueneutral change will decrease the negotiated wage rate, and

(b) a higher wage tax and higher tax exemption under government revenueneutral change will increase domestic labor demand and decrease international outsourcing.

It is important to emphasize that the impact of degree of wage tax progression is qualitatively similar in the absence of outsourcing. Then the wage tax parameters do not affect the mark-up of wage formation.

\section{V.2. Revenue-neutral changes in the composition of wage and payroll taxes}

Government can also raise the degree of average tax progression, i.e. $A R P \equiv t-t^{a}=\frac{t a}{w}$, when it increases $t$ and adjusts $s$ downwards. The effect of change 
in the composition of wage tax and payroll tax, which keeps the government taxrevenue $G=\left[t\left(w^{N}-a\right)+s w^{N}\right] L$ constant, can be written in terms of wage tax $t$ and payroll tax $s$ and allowing the change in wage negotiation $w^{N}$ in the absence of change in the wage tax exemption $a$ in the following way

$d G=0=\left(w^{N}-a\right) L d t+\left(w^{N} L+\left[t\left(w^{N}-a\right)+s w^{N}\right] L_{s}\right) d s+\left((t+s) L+\left(t\left(w^{N}-a\right)+s w^{N}\right) L_{w}\right) d w^{N}$

This can be written by using equation (5), i.e. $-\frac{L_{w} w}{L}=\eta^{f}=-\frac{L_{s}(1+s)}{L}$, as follows

$$
\left.d s\right|_{d G=0, d a=0}=-\frac{\left(w^{N}-a\right)(1+s)}{w^{N}\left[1+s-\left(t+s-\frac{t a}{w^{N}}\right) \eta^{f}\right]} d t-\frac{\left[(t+s)-\left(t+s-\frac{a}{w^{N}}\right) \eta^{f}\right](1+s)}{w^{N}\left[1+s-\left(t+s-\frac{t a}{w^{N}}\right) \eta^{f}\right]} d w^{N} .
$$

In this case the tax base of the wage tax, $(w-a) L$, is smaller than in the case of proportional payroll tax, $w L$. The total effect of changes in tax parameters $t$ and $s$ on the negotiated domestic wage rate is $d w^{N}=\frac{\partial w^{N}}{\partial t} d t+\frac{\partial w^{N}}{\partial s} d s$ and substituting the RHS of (18) for $d s$ gives after calculations as follows

$$
\left.\frac{d w^{N}}{d t}\right|_{d G=0, d a=0}=\frac{\frac{\partial w^{N}}{\partial t} w^{N}\left[1-\left(t+s-\frac{t a}{w^{N}}\right)(1+s)^{-1} \eta^{f}\right]-\frac{\partial w^{N}}{\partial s}\left(w^{N}-a\right)}{E},
$$

where in the assumption of the presence of the positive Laffer curve the denominator $E=w^{N}\left[1-\left(t+s-\frac{t a}{w^{N}}\right)(1+s)^{-1} \eta^{f}\right]+\frac{\partial w^{N}}{\partial s}\left[t+s-\left(t+s-\frac{t a}{w^{N}}\right) \eta^{f}\right]>0 \quad$ in $\quad$ (19) is positive, so that the direct effects of payroll tax dominate the behavioral responses (see Appendix C). If we are in the upward-sloping part of the Laffer curve a revenueneutral increase in wage tax parameter $t$ goes along with a lower payroll tax $s$. 
Concerning the sign of nominator of (19), we have under the assumption $\left[t+s-\left(t+s-\frac{t a}{w^{N}}\right) \eta^{f}\right]>0 \quad$ so that it is positive if $\frac{\partial w^{N}}{\partial s} \leq 0 \quad$ as $\beta \geq \frac{2(\delta-1)}{\left(2+(1+\delta) \gamma \frac{M^{*}}{L^{*}}\right)^{2}+2(\delta-1)}=F$ according to equation (13). Therefore, higher wage tax and lower payroll tax increase the negotiated wage under Nash wage bargaining if the bargaining power of labor union is higher or equal to the threshold $F$. If the bargaining power of the labor union is low enough, then $\frac{\partial w^{N}}{\partial s}>0$ so that the total effect of a change in the composition of wage tax and payroll tax on the negotiated wage $w^{N}$ is a priori ambiguous.

In this model in the absence of outsourcing equation (19) in the case $\frac{\partial w^{N}}{\partial s}=0$ can be written as

$$
\left.\frac{d w^{N}}{d t}\right|_{d G=0, d a=0, M=0}=\frac{\frac{\partial w^{N}}{\partial t} w^{N}\left[1-\left(t+s-\frac{t a}{w^{N}}\right)(1+s)^{-1} \delta\right]}{w^{N}\left[1-\left(t+s-\frac{t a}{w^{N}}\right)(1+s)^{-1} \delta\right]}=\frac{\partial w^{N}}{\partial t}=\frac{\beta+\delta-1}{\delta-1} \frac{b-a}{(1-t)^{2}}>0
$$

as $b>a$ so that increasing wage tax $t$ and decreasing payroll tax $s$ (to keep tax exemption $a$ constant) will increase the negotiated wage setting which is also qualitatively same as in the case if the bargaining power of labor union is higher or equal to the threshold $F$.

The total employment and outsourcing effects of changes in wage tax parameter $t$ and payroll tax parameter $s$ and the negotiated wage on employment and outsourcing are $d L=L_{w} d w^{N}+L_{s} d s$ and $d M=M_{w} d w^{N}+M_{s} d s$. These give using (4a), (4b) and (19) after calculations when $L_{w}=L_{s} \frac{(1+s)}{w^{N}}$ and $M_{w}=M_{s} \frac{(1+s)}{w^{N}}$ the following results (see Appendix C) 


$$
\begin{aligned}
& \left.\frac{d L}{d t}\right|_{d G=0, d a=0}=\underbrace{\frac{L_{s}(1+s)(1-t)}{w^{N} Y}}_{-}\left(\left[\frac{d w^{N}}{d t}\right]_{d G=0, d a=0}-\frac{\left(w^{N}-a\right)}{1-t}\right)\left\{\begin{array}{l}
> \\
=
\end{array}\right\} \text { as } a\left\{\begin{array}{l}
> \\
=
\end{array}\right\} 0 \\
& \left.\frac{d M}{d t}\right|_{d G=0, d a=0}=\underbrace{\frac{M_{s}(1+s)(1-t)}{w^{N} Y}}_{+}\left(\left[\frac{d w^{N}}{d t}\right]_{d G=0, d a=0}-\frac{\left(w^{N}-a\right)}{(1-t)}\right)\left\{\begin{array}{l}
< \\
=
\end{array}\right\} \text { as } a\left\{\begin{array}{l}
> \\
=
\end{array}\right\} 0
\end{aligned}
$$

where $Y=1+s-\left(t+s-\frac{t a}{w^{N}}\right) \eta^{f}$ and $\left[\frac{d w^{N}}{d t}\right]_{d G=0, d a=0}-\frac{\left(w^{N}-a\right)}{(1-t)}<0$ in the case of positive wage tax exemption. Therefore, a lower payroll tax and a higher wage tax to keep tax revenue-neutrality constant will increase domestic employment and decrease outsourcing. But if both taxes are proportional so that the tax bases are equal, then revenue-neutral changes in the composition of wage tax and payroll tax become irrelevant so that these do not affect domestic employment and outsourcing (see equation (C10) in Appendix C). ${ }^{15}$

In the absence of outsourcing equation (20a) by using equation (C6) from Appendix C can be written as

$$
\left.\frac{d L}{d t}\right|_{d G=0, d a=0, M=0}=\underbrace{\frac{L_{s}(1+s)(1-t)}{w^{N} Y}}_{-}\left(\left[\frac{d w^{N}}{d t}\right]_{d G=0, d a=0, M=0}-\frac{\left(w^{N}-a\right)}{1-t}\right)=\underbrace{\frac{L_{s}(1+s)(1-t)}{w^{N} Y}}_{-}\left(\frac{\partial w^{N}}{\partial t}-\frac{\left(w^{N}-a\right)}{1-t}\right)
$$

where $\left.\left(\frac{\partial w^{N}}{\partial t}-\frac{\left(w^{N}-a\right)}{1-t}\right)\right|_{M=0}=-\frac{\beta a}{(\delta-1)(1-t)}<0$ as $a>0$ so that $\left.\frac{d L}{d t}\right|_{d G=0, d a=0, M=0}>0$ as $a>0$. This means that also in the absence of outsourcing increasing wage tax $t$ and decreasing payroll tax $s$ will increase domestic labor demand in the presence of tax exemption. But if both taxes are proportional, then also in the absence of outsourcing

$15 \quad$ Heijdra and Ligthart (2009) have studied a simple labor tax reform of reducing a payroll tax and increasing a progressive wage tax in a search and matching model along the lines of Pissarides (2000) in a micro-founded macroeconomic model of a small open economy but in the absence of outsourcing. They argue that such a strategy increases employment. Like in our paper they have also abstracted from physical capital, which is an important new research topic. 
the employment effect of a change in wage and payroll tax to keep government revenue constant is zero. ${ }^{16}$

We can now summarize our findings of revenue-neutral change in lower payroll tax and higher wage tax in terms of wage formation, domestic employment and international outsourcing as follows.

Proposition 3: In the presence of flexible outsourcing and imperfectly competitive domestic labor markets

(a) a lower payroll tax and higher wage tax under revenue-neutral change increase the negotiated wage rate with sufficiently strong labor market imperfections, and it will have an ambiguous effect with sufficiently weak labor market imperfections, and

(b) a lower payroll tax and higher wage tax under revenue-neutral change will increase domestic labor demand and decrease international outsourcing in the presence of wage tax exemption, and

(c) in the absence of outsourcing a lower payroll tax and a higher wage tax under revenue-neutral change will also increase domestic labor demand in the presence of wage tax exemption, whereas

(d) in the absence of wage tax exemption the revenue-neutral changes in the composition of wage tax and payroll tax do not affect domestic employment and outsourcing.

It is important to emphasize that the impact of a lower payroll tax and higher wage tax under revenue-neutral change is qualitatively, but not quantitatively, similar both in the presence and in the absence of outsourcing in the case of the positive Laffer curve.

\section{Conclusions}

16 In the absence of outsourcing this has been shown e.g. in Koskela and Schöb (1999). 
We have studied in this paper the following questions under homogenous domestic labor market and outsourcing: What are the effects of outsourcing costs, productivity of outsourcing, and domestic wage and payroll tax levied on firms on the wage elasticity of labor demand in the presence of flexible outsourcing? What are the effects of outsourcing costs and productivity of outsourcing, wage tax, tax exemption and payroll tax on wage formation in an imperfectly competitive labor market when labor unions and firms negotiate wages under Nash bargaining? Finally, and importantly, what are the effects of two alternative labor tax reforms on domestic wage setting and domestic employment as well as on outsourcing in the case of government revenue neutral changes in terms of labor tax reforms. Wage taxation in OECD countries is progressive though the degree of progressivity varies across countries, while payroll taxes are approximately proportional. These are new research topics in the case of outsourcing by focusing the role of revenue-neutral labor tax reforms under Nash wage bargaining.

We have shown that in the presence of flexible outsourcing the wage elasticity of domestic labor demand is a decreasing function of the outsourcing cost and an increasing function of the wage rate and payroll tax of domestic labor and productivity of outsourcing. With sufficiently strong (weak) labor market imperfections a lower outsourcing cost and higher payroll tax have a wage-moderating (wage-increasing) effect. Polar cases are a monopoly labor union, with which lower outsourcing cost moderates wages, and the absence of labor market imperfections, in which case there is no relationship between outsourcing cost and wage rate and between payroll tax and wage rate. In the presence of flexible outsourcing the wage tax has a positive effect and the tax exemption a negative effect on the negotiated wage. In the absence of outsourcing payroll tax will have no effect on the negotiated wage.

Increasing the degree of tax progression under Nash wage bargaining, to keep the government tax revenue as constant has a wage-moderating effect and a positive effect on domestic employment and a negative effect on outsourcing. These qualitative results on wage formation and domestic employment are qualitatively similar, but 
quantitatively different both in the case of monopoly labor union and in the absence of outsourcing.

We have also shown that in the presence of flexible outsourcing a revenueneutral increase in the degree of wage tax progression by raising the wage tax and the tax exemption will decrease the negotiated wage rate, and will increase domestic labor demand and decrease international outsourcing. Finally, we have shown when the economy is on an upward-sloping part of the Laffer curve, a lower payroll tax and a higher wage tax rate under a revenue-neutral change increase the negotiated wage rate with sufficiently strong labor market imperfections, and it will have an ambiguous effect with sufficiently weak labor market imperfections. A lower payroll tax and higher wage tax under revenue-neutral change will increase domestic labor demand and decrease international outsourcing in the presence of wage tax exemption. But if both taxes are proportional, so that the tax bases are equal then revenue-neutral changes in the composition of wage tax and payroll tax do not affect domestic employment and outsourcing Also in the absence of outsourcing a lower payroll tax and a higher wage tax under revenue-neutral change will increase domestic labor demand in the presence of wage tax exemption. But if both taxes are proportional, then the employment effects of a change in wage and payroll tax to keep government revenue constant are zero.

Future research might take several new directions. We have completely neglected the role of physical capital in production as a means to affect the resources spent on outsourcing. Allowing for physical capital could broaden the income tax base. If domestic labor and capital are complements in production - and as long as the government lacks a direct instrument for controlling outsourcing - capital income taxation might be a useful tool to increase the productivity of domestic labor. The interpretations of our model could also most likely be extended to cover foreign direct investment (FDI) in a world with labor, domestic and foreign, as the only production factor in the following respect. The implications of outsourcing and FDIs are related aspects. An increase in the opportunities for outsourcing and FDI tends to increase the labor demand elasticity, but there may also be other strategic effects of outsourcing and FDI. In the long run the firm could commit to an FDI program, which makes it possible to exploit low-cost workers in the foreign country with no labor market imperfections. 
Within such a framework the crucial mechanism of our model focuses on how firms can make use of strategic FDI-commitments as a wage-moderating device. Interestingly, the strategic wage-moderating effect of the FDI may be realized with no reference to potential product market imperfections. ${ }^{17}$

Moreover, the resources that domestic firms spend on outsourcing will give rise to welfare effects in other countries. This suggests that uncoordinated policies might be inefficient from the perspective of society as a whole, and that outsourcing may provide an argument for policy coordination across countries. This has been studied by Aronsson and Sjögren (2004) in the absence of outsourcing.

\section{Appendix A: Implicit Nash wage bargaining solution}

Taking labor demand (4a) and outsourcing (4b) into account we find

$$
\begin{aligned}
\frac{\pi_{w}^{*}}{\pi^{*}} & =-\frac{1}{w} \frac{w(1+s) L}{\pi}=-\frac{1}{w\left[R-R_{L} L-\frac{1}{2} R_{M} M\right]} \frac{(L+\gamma M)^{-\frac{1}{\delta}} L}{w\left[\frac{\delta}{\delta-1}(L+\gamma M)^{\frac{\delta-1}{\delta}}-(L+\gamma M)^{-\frac{1}{\delta}} L-\frac{1}{2} \gamma M(L+\gamma M)^{-\frac{1}{\delta}}\right]}=-\frac{1}{w} \frac{(\delta-1)}{\left[1+\frac{(1+\delta)}{2} \frac{\gamma M}{L}\right]},
\end{aligned}
$$

which gives (9b). Substituting equations (9a) and (9b) into the first-order condition (8) gives

$$
\left(\beta w\left(1-\eta^{f}\right)(1-t)+\beta(b-t a) \eta^{f}\right)\left(2-\delta+\eta^{f}\right)=(1-\beta)(w(1-t)-(b-t a)) 2(\delta-1),
$$

and (A2) implies the implicit Nash bargaining solution (10). QED.

\footnotetext{
$17 \quad$ Glass and Saggi (1999, 2001) have theoretically studied the consequences of foreign direct investment (FDI) policies in a general equilibrium setting with several oligopolistic industries. They find that higher international outsourcing lowers the relative wage of domestic workers and increases the profits, creating greater incentives for innovation.
} 


\section{Appendix B: Nash wage bargaining, outsourcing cost and payroll tax}

By differentiation of Nash wage bargaining equation (10) with respect to the wage rate and outsourcing cost gives $\frac{\partial w}{\partial c}=\frac{A_{c}^{f} \hat{b}}{1-A_{w}^{f} \hat{b}}$ and substituting $\hat{b}=\frac{w}{A^{f}}$ from (10) for $\hat{b}$ gives

$$
\frac{\partial w^{N}}{\partial c}=\frac{\frac{A_{c}^{f} w}{A^{f}}}{1-\frac{A_{w}^{f} w}{A^{f}}} .
$$

Using the notation $X=\beta\left(\eta^{f}-1\right) Z+(1-\beta) 2(\delta-1)$, where $Z=2+(1+\delta) \gamma \frac{M^{*}}{L^{*}}$, and differentiating the mark-up $A^{f}=\frac{X+\beta Z}{X}$ from (11) with respect to outsourcing cost $c$ gives

$$
\begin{aligned}
A_{c}^{f} & =\frac{X\left(\beta Z \eta_{c}^{f}+\beta \eta^{f} Z_{c}\right)-(X+\beta Z)\left(\beta Z \eta_{c}^{f}+\beta\left(\eta^{f}-1\right) Z_{c}\right)}{X^{2}} \\
& =\frac{-\beta^{2} Z^{2} \eta_{c}^{f}+\left(\beta X-\beta^{2} Z\left(\eta^{f}-1\right)\right) Z_{c}}{X^{2}}=\frac{-\beta^{2} Z^{2} \eta_{c}^{f}+\beta(1-\beta) 2(\delta-1) Z_{c}}{X^{2}} .
\end{aligned}
$$

By using $Z_{c}=(1+\delta) \gamma \frac{M}{L}\left(\frac{M_{c} c}{M}-\frac{L_{c} c}{L}\right)=-(1+\delta) \gamma \frac{M^{*}}{L^{*}}\left(1+\gamma \frac{M^{*}}{L^{*}}\right)=\eta_{c}^{f}<0 \quad$ equation (B2) can be written as

$$
A_{c}^{f}=\frac{-\beta \eta_{c}^{f}\left(\beta\left[Z^{2}+2(\delta-1)\right]-2(\delta-1)\right)}{X^{2}} .
$$

The effect of outsourcing cost on the nominator of equation (B1) depends on the relative bargaining power of the labor union and the threshold as follows

$$
\begin{aligned}
& A_{c}^{f}\left\{\begin{array}{l}
> \\
= \\
<
\end{array}\right\} 0 \text { as } \beta\left\{\begin{array}{l}
> \\
= \\
<
\end{array}\right\} \frac{2(\delta-1)}{\left(2+(1+\delta) \gamma \frac{M^{*}}{L^{*}}\right)^{2}+2(\delta-1)} \\
& \text { so that } \frac{A_{c}^{f} w}{A^{f}}\left\{\begin{array} { l } 
{ > } \\
{ = } \\
{ < }
\end{array} 0 \text { as } \beta \left\{\begin{array}{l}
> \\
=\left\{\begin{array}{l}
2(\delta-1) \\
<
\end{array} \frac{M^{*}}{\left(2+(1+\delta) \gamma \frac{L^{*}}{L^{2}}+2(\delta-1)\right.}\right.
\end{array}\right.\right.
\end{aligned}
$$


Differentiating the mark-up with respect to the wage rate gives by using $Z_{w}=\eta_{w}^{f}>0$

$$
\begin{aligned}
A_{w}^{f} & =\frac{X\left(\beta Z \eta_{w}^{f}+\beta \eta^{f} Z_{w}\right)-(X+\beta Z)\left(\beta Z \eta_{w}^{f}+\beta\left(\eta^{f}-1\right) Z_{w}\right)}{X^{2}} \\
& =\frac{-\beta \eta_{w}^{f}\left(\left[\left(\beta\left(Z^{2}+2(\delta-1)\right]-2(\delta-1)\right)\right.\right.}{X^{2}}
\end{aligned}
$$

so that the effect of the wage rate on the mark-up is

$$
A_{w}^{f}\left\{\begin{array}{l}
< \\
>
\end{array}\right\} 0 \text { as } \beta\left\{\begin{array}{l}
> \\
<
\end{array}\right\} \frac{2(\delta-1)}{\left(2+(1+\delta) \gamma \frac{M^{*}}{L^{*}}\right)^{2}+2(\delta-1)}
$$

By using (B3) and (B5) the equation (B1) can be expressed as follows

$$
\begin{aligned}
\frac{\partial w^{N}}{\partial c}= & \frac{\frac{A_{c}^{f} w}{A^{f}}}{1-\frac{A_{w}^{f} w}{A^{f}}}=\left(\frac{-\frac{\beta \eta_{c}^{f} w\left(\beta\left[Z^{2}+2(\delta-1)\right]-2(\delta-1)\right)}{X(X+\beta Z)}}{\frac{X(X+\beta Z)+\beta \eta_{w}^{f} w\left(\beta\left[Z^{2}+2(\delta-1)\right]-2(\delta-1)\right)}{X(X+\beta Z)}}\right) \\
& =\frac{-\beta \eta_{c}^{f} w\left(\beta\left[Z^{2}+2(\delta-1)\right]-2(\delta-1)\right)}{X(X+\beta Z)+\beta \eta_{w}^{f} w\left(\beta\left[Z^{2}+2(\delta-1)\right]-2(\delta-1)\right)}
\end{aligned}
$$

where the denominator is positive so that we have

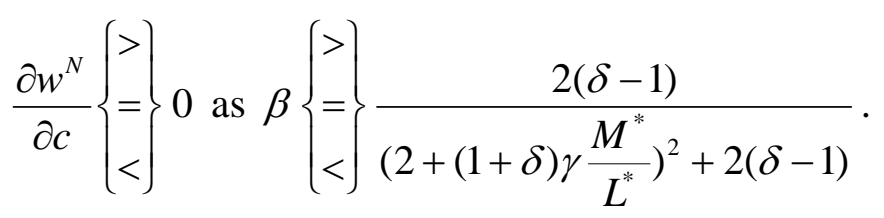

By differentiation of Nash wage bargaining equation (10) with respect to the wage rate and payroll tax gives

$$
\frac{\partial w^{N}}{\partial s}=\frac{\frac{A_{s}^{f} w}{A^{f}}}{1-\frac{A_{w}^{f} w}{A^{f}}} .
$$

Using $X=\beta\left(\eta^{f}-1\right) Z+(1-\beta) 2(\delta-1)$, and $Z=2+(1+\delta) \gamma \frac{M^{*}}{L^{*}}$, differentiating the mark-up $A^{f}=\frac{X+\beta Z}{X}$ from (10) with respect to payroll tax $s$ gives 


$$
\begin{aligned}
A_{s}^{f} & =\frac{X\left(\beta Z \eta_{s}^{f}+\beta \eta^{f} Z_{s}\right)-(X+\beta Z)\left(\beta Z \eta_{s}^{f}+\beta\left(\eta^{f}-1\right) Z_{s}\right)}{X^{2}} \\
& =\frac{-\beta^{2} Z^{2} \eta_{s}^{f}+\left(\beta X-\beta^{2} Z\left(\eta^{f}-1\right)\right) Z_{s}}{X^{2}}=\frac{-\beta^{2} Z^{2} \eta_{s}^{f}+\beta(1-\beta) 2(\delta-1) Z_{s}}{X^{2}}
\end{aligned}
$$

and $Z_{s}=(1+\delta) \gamma \frac{M}{(1+s) L}\left(\frac{M_{s}(1+s)}{M}-\frac{L_{s}(1+s)}{L}\right)=(1+\delta) \gamma \frac{M^{*}}{(1+s) L^{*}}\left(1+\gamma \frac{M^{*}}{L^{*}}\right)=\eta_{s}^{f}>0$ so that equation (B9) can be written as

$$
A_{s}^{f}=\frac{-\beta \eta_{s}^{f}\left(\beta\left[Z^{2}+2(\delta-1)\right]-2(\delta-1)\right)}{X^{2}}
$$

The effect of outsourcing cost on the mark-up under Nash wage bargaining depends on the relative bargaining power of the labor union as

$$
\begin{aligned}
& A_{s}^{f}\left\{\begin{array}{l}
< \\
>
\end{array}\right\} 0 \text { as } \beta\left\{\begin{array}{l}
> \\
<
\end{array}\right\} \frac{2(\delta-1)}{\left(2+(1+\delta) \gamma \frac{M^{*}}{L^{*}}\right)^{2}+2(\delta-1)} \\
& \text { so that } \frac{A_{s}^{f} w}{A^{f}}\left\{\begin{array}{l}
< \\
>
\end{array}\right\} 0 \text { as } \beta\left\{\begin{array}{l}
> \\
= \\
<
\end{array}\right\} \frac{2(\delta-1)}{\left(2+(1+\delta) \gamma \frac{M^{*}}{L^{*}}\right)^{2}+2(\delta-1)} \text {. }
\end{aligned}
$$

By using (B10) and (B5) the equation (B9) can be expressed as follows

$$
\begin{aligned}
\frac{\partial w^{N}}{\partial s}= & \frac{\frac{A_{s}^{f} w}{A^{f}}}{1-\frac{A_{w}^{f} w}{A^{f}}}=\left(\frac{-\frac{\beta \eta_{s}^{f} w\left(\beta\left[Z^{2}+2(\delta-1)\right]-2(\delta-1)\right)}{X(X+\beta Z)}}{\frac{X(X+\beta Z)+\beta \eta_{w}^{f} w\left(\beta\left[Z^{2}+2(\delta-1)\right]-2(\delta-1)\right)}{X(X+\beta Z)}}\right) \\
& =\frac{-\beta \eta_{s}^{f} w\left(\beta\left[Z^{2}+2(\delta-1)\right]-2(\delta-1)\right)}{X(X+\beta Z)+\beta \eta_{w}^{f} w\left(\beta\left[Z^{2}+2(\delta-1)\right]-2(\delta-1)\right)}
\end{aligned}
$$

where the denominator is positive so that we have the following conclusion

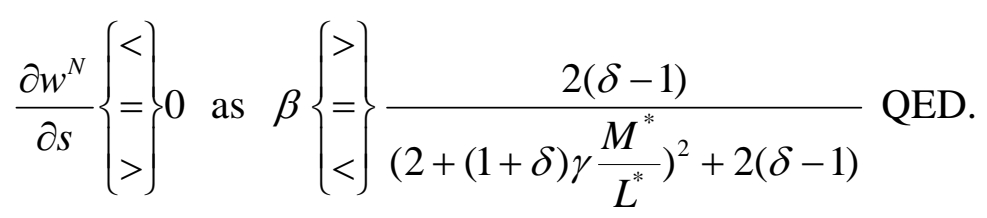




\section{Appendix C: Revenue-neutral labor tax reform calculations associated with wage formation, employment and outsourcing}

Substituting equations (14a) and (14b) into the numerator or equation (16) yields

$\frac{\partial w^{N}}{\partial t}+\left(\frac{\left.w^{N}-a\right)}{t}\right) \frac{\partial w^{N}}{\partial a}=\frac{A^{f} \frac{(b-a)}{(1-t)}-A^{f} \frac{t\left(w^{N}-a\right)}{t}}{(1-t)\left(1-\frac{A_{w}^{f} w}{A^{f}}\right)}=\frac{A^{f}\left[\frac{b-t a}{1-t}-w^{N}\right]}{(1-t)\left(1-\frac{A_{w}^{f} w}{A^{f}}\right)}=\frac{A^{f}\left[\hat{b}-w^{N}\right]}{(1-t)\left(1-\frac{A_{w}^{f} w}{A^{f}}\right)}<0$

because $w^{N}>\hat{b}$ in the presence of the mark-up $A^{f}>1$.

Concerning the denominator of (16) the total differential of government revenue $G=\left[t\left(w^{N}-a\right)+s w^{N}\right] L$ in terms of wage rate and employment via tax exemption yields $d G=-t L d a+(t+s) L \frac{\partial w^{N}}{\partial a} d a+\left(t\left(w^{N}-a\right)+s w^{N}\right) L_{w} \frac{\partial w^{N}}{\partial a} d a$. This gives

$$
\frac{d G}{d a}=-t L\left[1-\frac{\partial w^{N}}{\partial a}\left(1+\frac{s}{t}\right)\left(1-\eta^{f}\right)+\frac{a}{w^{N}} \eta^{f}\right]=-t L D<0
$$

under the positive Laffer curve assumption so that the denominator in (16) is positive, i.e., $D>0$, under the assumption that the direct effects of tax exemption dominate the behavioral responses and will have a negative effect on government revenue.

Substituting the RHS of (18) for $d s$ in $d w^{N}=\frac{\partial w^{N}}{\partial t} d t+\frac{\partial w^{N}}{\partial s} d s$ gives equation (19) $d w^{N}=\frac{\partial w^{N}}{\partial t} d t-\frac{\frac{\partial w^{N}}{\partial s}\left(w^{N}-a\right)(1+s)}{w^{N}\left[1+s-\left(t+s-\frac{t a}{w^{N}}\right) \eta^{f}\right]} d t-\frac{\frac{\partial w^{N}}{\partial s}\left[t+s-\left(t+s-\frac{t a}{w^{N}}\right) \eta^{f}\right](1+s)}{w^{N}\left[1+s-\left(t+s-\frac{t a}{w^{N}}\right) \eta^{f}\right]} d w^{N}$ so that 


$$
\begin{aligned}
& \left.\frac{d w^{N}}{d t}\right|_{d G=0, d a=0}=\frac{\left(\frac{\partial w^{N}}{\partial t}-\frac{\frac{\partial w^{N}}{\partial s}\left(w^{N}-a\right)(1+s)}{w^{N}\left[1+s-\left(t+s-\frac{t a}{w^{N}}\right) \eta^{f}\right]}\right)}{\left(1+\frac{\frac{\partial w^{N}}{\partial s}\left[t+s-\left(t+s-\frac{t a}{w^{N}}\right) \eta^{f}\right](1+s)}{w^{N}\left[1+s-\left(t+s-\frac{t a}{w^{N}}\right) \eta^{f}\right]}\right)} \\
& =\frac{\frac{\partial w^{N}}{\partial t} w^{N}\left[1-\left(t+s-\frac{t a}{w^{N}}\right)(1+s)^{-1} \eta^{f}\right]-\frac{\partial w^{N}}{\partial s}\left(w^{N}-a\right)}{w^{N}\left[1-\left(t+s-\frac{t a}{w^{N}}\right)(1+s)^{-1} \eta^{f}\right]+\frac{\partial w^{N}}{\partial s}\left[t+s-\left(t+s-\frac{t a}{w^{N}}\right) \eta^{f}\right]}
\end{aligned}
$$

Concerning the denominator of (C4) the total differential of government revenue $G=\left[t\left(w^{N}-a\right)+s w^{N}\right] L$ in terms of wage rate and employment and via payroll tax is $d G=\left[w^{N} L+\left(t\left(w^{N}-a\right)+s w^{N}\right) L_{s}\right] d s+(t+s) L \frac{\partial w^{N}}{\partial s} d s+\left(t\left(w^{N}-a\right)+s w^{N}\right) L_{w} \frac{\partial w^{N}}{\partial s} d s$, which can be expressed as

$$
\frac{d G}{d s}=L\left[w^{N}\left(1-\frac{\left(t+s-\frac{t a}{w^{N}}\right)}{(1+s)} \eta^{f}\right)+\frac{\partial w^{N}}{\partial s}\left[t+s-\left(t+s-\frac{t a}{w^{N}}\right) \eta^{f}\right]=L E>0\right.
$$

so that $E>0$ under the assumption that the direct effects of payroll tax dominate the behavioral responses, i.e. it will have a positive effect on government revenue in the presence of the positive Laffer curve. Using the RHS of (18) for $d s$ in $d L=L_{w} d w^{N}+L_{s} d s$ and $L_{w}=L_{s} \frac{(1+s)}{w^{N}}$ gives the following result

$$
\begin{gathered}
\left.\frac{d L}{d t}\right|_{d G=0, d a=0}=\underbrace{\left.L_{w} \frac{d w^{N}}{d t}\right|_{d G=0, d a=0}}_{-}+\underbrace{\left.L_{s} \frac{d s}{d t}\right|_{d G=0, d a=0}}_{+}=\frac{L_{s}(1+s)}{w^{N}} \frac{1-t}{1+s-\left(t+s-\frac{t a}{w^{N}}\right) \eta^{f}}\left[\frac{d w^{N}}{d t}\right]_{d G=0, d a=0} \\
-\frac{L_{s}(1+s)\left(w^{N}-a\right) / w^{N}}{1+s-\left(t+s-\frac{t a}{w^{N}}\right) \eta^{f}}=\underbrace{\frac{L_{s}(1+s)(1-t)}{w^{N} Y}}_{-}\left(\left[\frac{d w^{N}}{d t}\right]_{d G=0, d a=0}-\frac{\left(w^{N}-a\right)}{1-t}\right),
\end{gathered}
$$


where $Y=1+s-\left(t+s-\frac{t a}{w^{N}}\right) \eta^{f}$. And using the RHS of (18) for $d s$ in $d M=M_{w} d w^{N}+M_{s} d s$ gives after similar calculations when $M_{w}=M_{s} \frac{(1+s)}{w^{N}}$ the following result

$$
\begin{gathered}
\left.\frac{d M}{d t}\right|_{d G=0, d a=0}=\underbrace{\left.M_{w} \frac{d w^{N}}{d t}\right|_{d G=0, d a=0}}_{-}+\underbrace{\left.M_{s} \frac{d s}{d t}\right|_{d G=0, d a=0}}_{+}=\frac{M_{s}(1+s)}{w^{N}} \frac{1-t}{1+s-\left(t+s-\frac{t a}{w^{N}}\right) \eta^{f}}\left[\frac{d w^{N}}{d t}\right]_{d G=0, d a=0} \\
-\frac{M_{s}(1+s)\left(w^{N}-a\right) / w^{N}}{1+s-\left(t+s-\frac{t a}{w^{N}}\right) \eta^{f}}=\underbrace{\frac{M_{s}(1+s)(1-t)}{w^{N} Y}}_{+}\left(\left[\frac{d w^{N}}{d t}\right]_{d G=0, d a=0}-\frac{\left(w^{N}-a\right)}{(1-t)}\right) .
\end{gathered}
$$

In the presence of outsourcing equation (C4) can be written as

$$
\left.\frac{d w^{N}}{d t}\right|_{d G=0, d a=0}=\frac{\frac{\partial w^{N}}{\partial t} w^{N} \hat{X}}{\left[w^{N} \hat{X}+\frac{\partial w^{N}}{\partial s}(1+s) \hat{Y}\right]}-\frac{\frac{\partial w^{N}}{\partial s}(1+s)\left(w^{N}-a\right)}{\left[w^{N} \hat{X}+\frac{\partial w^{N}}{\partial s}(1+s) \hat{Y}\right]},
$$

where $\hat{Y}=t+s-\left(t+s-\frac{t a}{w^{N}}\right) \eta^{f}<\hat{X}=1+s-\left(t+s-\frac{t a}{w^{N}}\right) \eta^{f}$ and

$$
\frac{\left(w^{N}-a\right)}{(1-t)}=\frac{1}{1-t}\left(\frac{\left(w^{N}-a\right)\left(w^{N} \hat{X}+\frac{\partial w^{N}}{\partial s}(1+s) \hat{Y}\right.}{\left(w^{N} \hat{X}+\frac{\partial w^{N}}{\partial s}(1+s)\right.}\right) .
$$

Associated with equations (C6) and (C7) we now calculate the following

$$
\begin{aligned}
& \left(\left[\frac{d w^{N}}{d t}\right]_{d G=0, d a=0}-\frac{\left(w^{N}-a\right)}{(1-t)}\right)=\underbrace{\left[w^{N} \hat{X}+\frac{\partial w^{N}}{\partial s}(1+s) \hat{Y}\right]^{-1}}_{+} \cdot \\
& \left(\frac{\partial w^{N}}{\partial t} w^{N} \hat{X}-\frac{\partial w^{N}}{\partial s}(1+s)\left(w^{N}-a\right)-\frac{\left(w^{N}-a\right)}{(1-t)} w^{N} \hat{X}+\frac{\partial w^{N}}{\partial s}(1+s) \hat{Y}\right)=\underbrace{\left[w^{N} \hat{X}+\frac{\partial w^{N}}{\partial s}(1+s) \hat{Y}\right]^{-1}}_{+} . \\
& \left(\frac{\partial w^{N}}{\partial t} w^{N} \hat{X}-\frac{\left(w^{N}-a\right)}{(1-t)}\left[w^{N} \hat{X}+\frac{\partial w^{N}}{\partial s}(1+s)(1-t+\hat{Y})\right]\right) .
\end{aligned}
$$

Using $1-t+\hat{Y}=\hat{X}$ equation (C9) can be rewritten as follows 


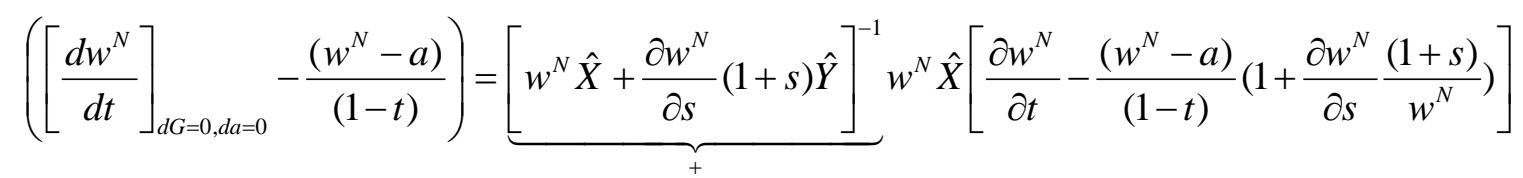

By using equation (13) one can show that $1+\frac{\partial w^{N}}{\partial s} \frac{1+s}{w^{N}}=\frac{1}{1-\frac{A_{w}^{f} w}{A^{f}}}>1$ which implies that

$\frac{\partial w^{N}}{\partial t}-\frac{\left(w^{N}-a\right)}{(1-t)}\left(1+\frac{\partial w^{N}}{\partial s} \frac{(1+s)}{w^{N}}\right)=\frac{\partial w^{N}}{\partial t}-\frac{\left(w^{N}-a\right)}{(1-t)}\left(1-\frac{A_{w}^{f} w}{A^{f}}\right)^{-1}=$

$\left(1-\frac{A_{w}^{f} w}{A^{f}}\right)^{-1}\left[A^{f} \frac{b-a}{(1-t)^{2}}-A^{f} \frac{b-t a}{(1-t)^{2}}+a(1-t)\right]=\left(1-\frac{A_{w}^{f} w}{A^{f}}\right)^{-1}\left[a\left(1-A^{f}\right)\right]<0$.

Therefore, in the presence of outsourcing we have

$\left(\left[\frac{d w^{N}}{d t}\right]_{d G=0, d a=0}-\frac{\left(w^{N}-a\right)}{(1-t)}\right)\left\{\begin{array}{l}> \\ =\end{array} 0\right.$ as $a\left\{\begin{array}{l}> \\ =\end{array}\right\}$. QED.

\section{References:}

Acemoglu, D. and Zilibotti (2001): Productivity Differences, The Quarterly Journal of Economics, 116 (2), 563-606.

Aronsson, T. and T. Sjögren (2004): Efficient Taxation, Wage Bargaining and Policy Coordination, Journal of Public Economics, 88, 2711-2725,

Cahuc, P. and A. Zylberberg (2004): Labor Economics, the MIT Press.

Danthine, J.-P. and J. Hunt (1994): Wage Bargaining Structure, Employment and Economic Integration, the Economic Journal, 104, 528-541.

Dixit, A.K. and J.E. Stiglitz (1977): Monopolistic Competition and Optimal Product Diversity, American Economic Review, 67, 297-308.

Eckel, C. and H. Egger (2006): Wage Bargaining and Multinational Firms In General Equilibrium, CESifo Working Paper No. 1711.

Ethier, W.J. (2005): Globalization, Globalisation: Trade, Technology, and Wages, International Review of Economics and Finance, 14, 237-258.

Fullerton, D. (1982): On the Possibility of an Inverse Relationship between Tax Rates and Government Revenues, Journal of Public Economics, 19, 3-22.

Glass, A.J. and K. Saggi (1999): FDI Policies under Shared Factor Markets, Journal of International Economics, 49, 309-332.

Glass, A.J. and K. Saggi (2001): Innovation and Wage Effects of International Outsourcing, European Economic Review, 45, 67-86.

Görg, H. and A. Hanley (2005): Labor Demand Effects of International Outsourcing: Evidence from Plant-Level Data, International Review of Economics and Finance, 14, 365-376.

Hakkala, K., F. Heyman and F. Sjöholm (2009): Cross-Border Acquisitions, Multinationals and Wage Elasticities, Research Institute of Industrial Economics (IFN) Working Paper 709, Stockholm, Sweden. 
Hasan, R., D. Mitra and R.V. Ramaswamy (2007): Trade Reforms, Labor Regulations, and Labor Demand Elasticities: Empirical Evidence from India, the Review of Economics and Statistics, 89, 466-481.

Heijdra, B.J. and J.E. Ligthart (2009): Labor Tax Reform, Unemployment, and Search, International Tax and Public Finance, 16, 82-104.

Hijzen, A., H. Görg and R.C. Hine (2005): International Outsourcing and the Skill Structure of Labour Demand in the United Kingdom, the Economic Journal, 115, 860-878.

Koskela, E. (2008): The Effects of Labour Tax Progression under Nash Wage Bargaining and Flexible Outsourcing, IZA Discussion Paper No. 3501.

Koskela, E. and R. Schöb (2008): Outsourcing of Unionized Firms and the Impact of Labour Market Policy Reforms, IZA Discussion Paper No. 3566, June, University of Bonn.

Koskela, E. and R. Schöb (1999): Does the Composition of Wage and Payroll Taxes Matter under Nash Bargaining?, Economics Letters, 64, 343-349.

Koskela, E. and R. Stenbacka (2008): Equilibrium Unemployment with Outsourcing under Labour Market Imperfections, article in press in: Labour Economics.

Koskela, E. and J. Vilmunen (1996): Tax Progression is Good for Employment in Popular Models of Trade Union Behaviour, Labour Economics, 3, 65-80.

Lambert, P.J. (2001): The Distribution and Redistribution of Income, $3^{\text {rd }}$ edition, Manchester University Press.

Lommerud, K.E., F. Meland and L. Sorgard (2006): National versus International Mergers in Unionized Oligopoly, the Rand Journal of Economics, 37, 212-233.

Lommerud, K.E., F. Meland and O.R. Straume (2009): Can Unionization Lead to International Outsourcing?, Journal of International Economics, 77, 109-119.

OECD (2004): Taxing Wages 2003-2004, OECD Paris.

Musgrave, R.A. and T. Thin (1948): Income Tax Progression, 1929-1948, Journal of Political Economy, 56, 498-514.

Pissarides, C.A. (2000): Equilibrium Unemployment Theory, The MIT Press (2nd edition).

Senses, M.Z. (2006): The Effects of Outsourcing on the Elasticity of Labor Demand, CES Discussion Paper, Washington D.C., March.

Sinn, H-W. (2007): The Welfare State and Forces of Globalization, CESifo Working Paper no 1925.

Skaksen, J.R. and J.R. Sörensen (2001): Should Trade Unions Appreciate Foreign Direct Investment, Journal of International Economics, 55, 379-390.

Slaughter, M. (2001): International Trade and Labor Demand Elasticities, Journal of International Economics, 54, 27-56.

Skaksen, J.R. (2004): International Outsourcing When Labour Markets are Unionized, Canadian Journal of Economics, 37(1), 78-94.

Trabandt, M. and H. Uhlig (2006): How Far Are We from the Slippery Slope? The Laffer Curve Revisited, SFB 649 Discussion Paper 2006-023, HumboldtUniversität zu Berlin.

Zhao, L. (1998): The Impact of Foreign Direct Investment on Wages and Employment, Oxford Economic Papers, 50, 284-301. 